\title{
Goiânia: dinâmicas do patrimônio e da memória entre a instituição da cidade-monumento e a cidade-praticada: diálogos e desafios
}

Edmar Aparecido de Barra e Lopes*

Resumo: O processo de reconfiguração do campo do patrimônio cultural na atualidade tem desafiado os pesquisadores a compreender os usos sociais do passado e suas relações com a dinâmica da patrimonialização, compreendida como processo em um contexto demarcado pela expansão da memória e das dinâmicas identitárias. Percebe-se a construção desse novo horizonte profundamente interdisciplinar, assumindo destaque a grande recorrência das metodologias qualitativas a partir dos anos 1970 e 1980. Esse processo é também caracterizado pela desconstrução de dicotomias paradigmáticas: material $\mathrm{x}$ imaterial; cultura erudita $\mathrm{x}$ cultura popular; presente $\mathrm{x}$ passado; memória $\mathrm{x}$ história, etc. Este artigo desenvolve tal discussão a partir da análise de narrativas dominantes sobre o urbano e a cidade de Goiânia-GO e suas relações com duas distintas concepções de patrimônio cultural, desde a sua fundação, em 1937, até o final do século XX.

Palavras-chave: Patrimônio cultural. Patrimonialização. História. Memória. Cidade.

"Professor da Faculdade de Ciências Sociais (FCS) na Universidade Federal de Goiás (UFG). Doutorado em Ciências Sociais pela Universidade Estadual de Campinas (UNICAMP/SP).

E-mail: ed.clio@hotmail.com, http://orcid.org/0000-0002-1825-0097 
Goiânia: dinâmicas do patrimônio e da memória entre a instituição...

\section{Introdução}

As décadas recentes têm sido marcadas por uma grande produção e discussão nacional e internacional sobre a ideia dos lugares de memórias. Dessa forma, a discussão sobre o tema tornou-se imprescindível e profundamente interdisciplinar, entrando, assim, no domínio de inúmeros campos de saber por diversas vias (CHAGAS, 2015). O presente artigo se junta a essa produção visando problematizar a memória oficial vinculada à ideia de cidade-patrimônio ${ }^{1}$, particularmente de Goiânia-GO², como forma de dar visibilidade a outras cidades praticadas nesse processo (CERTEAU, 1994).

Diante disso, está presente a preocupação em desmistificar uma imagem da cidade de Goiânia tradicionalmente comemorada por suas elites, ou seja, a de um espaço monolítico de modernidade 3 . Uma vez que, como é conhecido, o processo de patrimonialização enquanto valorização de bens tem um caráter político, ou seja, a definição sobre aquilo que tem valor e o que não tem pressupõe uma escolha, uma seleção que se dá segundo padrões de aceitação social que tem uma historicidade (SCIFONI, 2006).

A história dessa cidade esteve marcada desde a sua fundação (1937) por uma ideia específica de patrimônio cultural, ou melhor, uma concepção sobre o mesmo produzida no contexto dos anos 1930, no governo Vargas, sob influência de intelectuais modernistas e no contexto de criação do Instituto do Patrimônio Histórico e Artístico Nacional (IPHAN). Portanto, predominando, a partir de então, uma noção de patrimônio histórico e artístico nacional vinculada à ideia de fatos memoráveis da história do Brasil ${ }^{4}$.

Nessa perspectiva, a eleição/construção da cidade-patrimônio de Goiânia enquanto vitrine da modernidade no cerrado resulta do processo de desqualificação e produção da invisibilidade de outras cidades, por conseguinte, do campo de diversas e não raramente conflitantes memórias inerentes a essas. Concordando com a análise segundo a qual falar de "[...] patrimonialização como processo de atribuição de valores culturais aos bens reconhecidos como patrimônio [...], é falar de coisas (ou práticas) cujas propriedades, derivadas de sua natureza material, são seletivamente mobilizadas pelas sociedades, grupos sociais, comunidades, para socializar, 
operar e fazer agir suas ideias, crenças, afetos, seus significados, expectativas, juízos, critérios, normas etc. [...], ou seja, seus valores” (MENESES, 2009).

Passemos agora à discussão intitulada $A$ cidade-postaP ou cidade-monumento, na qual trataremos sobre a construção da ideia de Goiânia enquanto tal. Em outras palavras, trata-se de um discurso vinculado ao modelo de patrimonialização supracitado e suas articulações com a historiografia tradicional local, bem como à memória citadina hegemônica.

\section{A instituição da cidade-monumento}

A cidade, e cada cidade, constitui-se, fundamentalmente, de uma multiplicidade de memórias. Entretanto, a articulação entre o saber e o poder nesse espaço, não raramente, contribui para a reprodução do espaço urbano enquanto instituição de uma temporalidade. Nesse contexto, pode-se dizer que a cidade de Goiânia tende a ser percebida, sobretudo, através de uma determinada ordem privilegiada de signos, ou seja, através de um compósito de produções em que as palavras assumem uma independência tal a ponto de representar as coisas independentemente de suas modificações históricas.

Esse distanciamento ideológico entre a cidade assim representada e as formas através das quais a realidade social é vivida por sua população pode ser constatado em várias práticas discursivas, tais como: a historiografia tradicional local; a narrativa comum da grande imprensa escrita local sobre a cidade (até final dos anos 1970); depoimentos de técnicos, burocratas e pioneiros sobre a construção de Goiânia e a própria base conceitual e metodológica que fundamenta a construção modernista da ideia de urbe concebida como cidade-postal/cidade-monumento, estruturada enquanto obra de arte. Descolada de sua dinâmica histórica multifacetada. Enaltecedora de uma memória sobre esta em detrimento de outras (SANT’ANNA, 1995; 2014; RIEGL, 2014).

$\mathrm{Na}$ maior parte dessa produção historiográfica, as imagens constituídas sobre Goiânia assumem uma característica também 
Goiânia: dinâmicas do patrimônio e da memória entre a instituição...

muito observada no que concerne a outras cidades, ou seja, traços demasiadamente unidimensionais sobre o urbano e a natureza de sua memória. Nesse jogo e/ou prática discursiva, a multiplicidade da memória sobre a cidade tende a ser reduzida a sua história oficial. Essa representação historiográfica sobre a cidade é responsável por uma narrativa em que, salvo raras exceções, privilegia-se um olhar pouco adequado para que seja possível conferir visibilidade às várias portas e janelas constitutivas desse espaço. De outro modo, essa visão de história dificulta a percepção daquilo que Michel de Certeau (1994) denomina de "cidade praticada", isto é, os vários e sempre renovados caminhos do espaço citadino. Trata-se de uma produção ininterrupta e diversa de territorialidades novas, surpreendentes em relação à arquitetura disciplinar do espaço capitalista, tal qual a ideia de cidade-patrimônio vinculada ao mesmo.

A indiferença da referida prática historiográfica perante este e tantos outros exemplos semelhantes de temas e/ou memórias malditas sobre a/s cidade/as (os movimentos de luta por moradia, as prostitutas, a infância, a música, o lazer, a cultura popular e outros) tem contribuído para a produção e/ou cristalização de imagens sobre a cidade de Goiânia. Essa imagem está pautada por uma perspectiva linear, de uma história contínua e factual, na qual as novas produções sugerem reedições do já conhecido. Nesse sentido, repensar as tradicionais imagens postais da mesma (cidade-moderna ${ }^{6}$; cidade-limpa; cidade-planejada; cidade-ecológica; cidade-tranquila etc.), através das quais se tem produzido uma relativa historiografia, exigiria, em certa medida, que escovássemos a contrapelo tal produção (BENJAMIN, 1991).

Sendo assim, Goiânia vem à tona como filha, por excelência, da modernidade, âncora fundamental do desenvolvimento econômico do Estado. Aparece ainda como expressivo e modelar exemplo de uma propalada nova mentalidade político-administrativa que deveria revolucionar a realidade econômica de Goiás (PALACIN; MORAES, 1975). É apresentada como o grande acontecimento do século XX na região.

Através dessa narrativa, ela nos aparece como um divisor de águas, fronteira entre o moderno e o antigo. Afigura-se como crivo através do qual se deve, respectivamente, repensar o passado e traçar 
o futuro do povo goiano e da própria vida econômica e política do Estado. De outra forma, Goiânia foi apresentada como "[...] o símbolo do moderno e do urbano em solo rural. Um teatro de art nouveau cravado no meio do Planalto Central" (CHAUL, 1997, p. 226). Assim, através de uma linguagem idílica, paisagística e, por conseguinte, conflitiva com o tempo da história que é pluridimensional, trazemos a descrição de Pedro Ludovico Teixeira (fundador de Goiânia), no lançamento de sua pedra fundamental:

Prevejo que dentro de cinco anos grande porção desta área destinada à cidade futura estará coberta, se não de luxuosas, alegres, vivendas em que os preceitos de higiene se casarão com o conforto e a beleza da arquitetura. Nos seus jardins, ornados principalmente de flores goianas, de arbustos genuinamente nossos, os habitantes encontrarão um ambiente próprio para se espairecerem às tardes, e as crianças o lugar adequado para se distraírem. Prestando-se esta topografia para campos de todos os esportes, é natural que se fará cultivo de todos, mormente dos que se praticam entre nós (TEIXEIRA, 1933 apud MONTEIRO, 1938).

Trata-se de uma das belas narrativas do compósito de recortes de memórias do poder oficial que contribui para percebermos como a elite local procurou construir a imagem de cidade-harmônica, a qual também alimentaria a ideia de cidade-postal ou cidade-monumento, vinculada ao paradigma de patrimonialização em questão. Um discurso, como lembra Chaves (1985, p. 19), “[...] marcado pela intenção de neutralidade e por uma proposta de homogeneização dos diferentes grupos sociais, [...] na tentativa de mascarar as contradições que opõem os diferentes grupos”.

Outra marca característica da historiografia tradicional local é a imagem da cidade como lugar de uma nova ordem (progressista), vista como obra dos "grandes homens". Esse era o discurso dos intelectuais goianos que, em consonância com o Estado Novo, "[...] procuravam inserir Pedro Ludovico Teixeira no ideal de homem cordial, justificando, assim, seu caráter ordeiro e o ganho que a sociedade teria com o seu governo" (CHAUL, 1997, p. 222). 
Goiânia: dinâmicas do patrimônio e da memória entre a instituição...

Nesse tipo de discurso, dificilmente poderemos perceber a cidade como resultante de forças sociais distintas em interação, pois o mesmo tende a ordenar e a interpretar os vários signos referentes a essa realidade urbana, de forma a produzir análises mecânicas e polarizadas da cidade, de forma a monumentalizar determinados lugares de memória e, por conseguinte, desqualificar algumas memórias em proveito de outras. Dessa maneira, corroborando uma ideia de patrimônio tal como descrita e historicizada anteriormente: um dos principais elementos instituintes da ideologia de Goiânia enquanto cidade-monumento.

À medida que esse tipo de discurso se instala em seus lugares privilegiados de produção e reprodução do saber (escolas, universidades, jornais etc.), consolida-se a ideia dessa localidade como: "[...] cidade dos antepassados, dos heróis fundadores, dos donos do poder de ontem e de hoje [...]"; cidade dos "[...] donos da letra [...] dos eruditos e historiadores, dos poetas da oficialidade e urbanistas, dos planejadores e tecnocratas" (MENEZES, 1985, p. 199). Também associada à ideia de cidade-locomotiva do progresso goiano. Dessa narrativa, vinculada ao modelo de patrimônio definido, estão alijadas as memórias citadinas associadas às práticas cotidianas de trabalhadores e trabalhadoras que experimentam a cidade de forma polissêmica.

Esse discurso, enquanto uma das bases do processo de patrimonialização em questão, concorreu e concorre para um processo no qual o município de Goiânia, pouco a pouco, é definido como um domínio próprio e distinto de outros espaços urbanos do estado de Goiás, o de cidade-monumento. Considerada símbolo de progresso e que, não raramente, se consolida alimentando um processo inverso de desqualificação ideológica recorrente, apoiado num tratamento discursivo que associa a cidade de Goiás (antiga capital), suas práticas cotidianas populares e temporalidades como contrassignos da ideia de modernidade.

Essa produção/reprodução do discurso referido, essa imagemsíntese da cidade, além de ser uma das ideias basilares do modelo modernista de patrimônio cultural, remete também aos novos interesses político-econômicos em cena. Trata-se da "[...] formação do espaço socioeconômico do Sul do Estado, revigorada com a nova 
política de ocupação do território efetivada pela interiorização que ficou conhecida, no discurso oficial, como a Marcha para o Oeste" (CHAVES, 1985, p. 6).

Esse processo foi responsável pela progressiva integração da espacialidade econômica goiana nos circuitos do capitalismo nacional em expansão (BORGES, 1982). Esse período da história de Goiás está na base da genealogia das ideias que orientaram essa nova concepção de cidade associada e alimentada também pelo paradigma de patrimônio cultural sobre o qual discorremos. De outra forma, podemos dizer, em grande medida, que Goiânia, antes de existir como espaço físico, existira como ação narrativa, pois foi também fruto do planejamento urbano e de todas as ideologias que este carrega através de suas práticas, em particular a abstração cidade-monumento.

É o projeto de um espaço próprio que circunscreve um lugar de produção de um sujeito (CERTEAU, 1994). Em outras palavras, produção do homem moderno, confinado ao ninho do tempo da produção. À medida que esse discurso vai se estabelecendo ou que essa cidade-ficção passa a fazer parte da rede de instituições citadinas (particularmente aquelas vinculadas aos processos de patrimonialização, norteados pela concepção de patrimônio cultural enquanto determinados bens culturais edificados ou tangíveis), temos - paralelamente - um mecanismo degolador de memórias antagônicas ou destoantes dessa ideia de cidade-patrimônio.

A produção e reprodução dessa memória oficial sobre o urbano, bem como de tal ideia de patrimônio, superpõe essa imagem de cidade instituída como sujeito universal às memórias da cidade vivenciada no cotidiano pelo homem comum, homem da rua. Desse modo, opera um projeto com o objetivo de transformar em página em branco o passado, de refazer a história (CERTEAU, 1994). A força e a influência dessa memória unívoca sobre a cidade foi muito eficaz para que significativa parte da produção histórica, sociológica e urbanística (tradicionais) referente à fundação, construção e urbanização de Goiânia ficasse profundamente marcada pelas limitações analíticas típicas do positivismo e funcionalismo, do idealismo, economicismo etc., abordagens nas quais a ideia de processo é confundida com as relações das estruturas entre si e onde 
Goiânia: dinâmicas do patrimônio e da memória entre a instituição...

a história tende a se mostrar como um conjunto ou somatória de conceitos que pairam sobre a dinâmica multiforme daquilo que Thompson (1981) denomina de "experiência humana".

Em outros termos, alimentou-se a necessidade teórico-metodológica atual de avançarmos no sentido de uma nova compreensão sobre o processo de produção e reprodução do espaço urbano, tal como do urbano, apreendidos através da análise histórica de práticas cotidianas localizadas e que constituem campos de tensão e disputas urbanas. Uma análise assim caracterizada impõe desmistificarmos as referidas práticas discursivas da cidade letrada (RAMA, 1989), privilegiando as relações da cultura letrada e o campo da oralidade criticamente tomado. Caminho potencial e promissor para uma releitura da história da construção e consolidação da cidade de Goiânia, bem como para repensarmos a concepção de patrimônio considerada, até o momento, em favor de uma abordagem mais crítica sobre o mesmo.

\section{Da cidade-monumento à cidade-praticada}

O processo de patrimonialização enquanto seleção analisado no início da primeira parte deste artigo (MENESES, 2009) permitenos concluir que o mesmo resulta numa operação de produção de cidades-malditas, cidades-silenciadas. Em outras palavras, na emergência de cidades impossíveis de serem acolhidas pelo citado modelo de patrimonialização, uma vez que este implicava no "[...] reconhecimento de um [...] determinado tipo de patrimônio, o patrimônio material dito histórico, mais precisamente o patrimônio constituído por edificações - patrimônio imóvel” (CHOAY, 2006).

Assim, entendemos ser eficaz problematizarmos tal processo de patrimonialização através do exercício de "escovar a história a contrapelo”. Dessa forma, subvertemos, a partir do presente, a racionalidade contemplativa das narrativas do progresso, cujos representantes identificam-se afetivamente com as classes dominantes, como afirma Benjamin (2005). Tal processo nos permitirá identificar e expor os limites ideológicos desse modelo de preservação de bens culturais, associado à reprodução de uma determinada memória 
dominante sobre a cidade, bem como à emergência e consolidação da concepção de patrimônio (imaterial), mais afinada à ideia de cidade no plural (CERTEUAU, 1994).

Trata-se de uma linha de problematização que assumimos, portanto, profundamente afinada com uma vasta e rica literatura recente que tem "escovado" em sentido contrário as tradicionais relações estabelecidas pela cidade das letras (RAMA, 1989) no que concerne às suas interfaces com a memória e a história, a cultura e o poder. Esse exercício teórico-metodológico foi desenvolvido com excelência - direta e indiretamente - por vários autores/as ${ }^{7}$.

As contribuições da literatura relacionada, além de outros inúmeros exemplos impossíveis de serem citados e/ou discutidos no âmbito deste artigo, têm fundamentado a compreensão segundo a qual a concepção de patrimônio vinculada à imagem de Goiânia, enquanto vitrine da modernidade no cerrado, tende a apresentar tudo que vemos nas ruas da cidade já ocupando "[...] um lugar no modelo da informação homogeneizada", de modo que, "[...] este mundo que vejo, este que costumamos reconhecer como o mundo, se apresenta a meus olhos - pelo menos em grande parte - já rotulado, definido, catalogado" (CALVINO, 1996, p. 139-140).

Nesse sentido, o mapa oficial de Goiânia, com seus consagrados lugares de memória (Praça Cívica, Praça dos Bandeirantes, Praça Joaquim Lúcio, Avenida Araguaia, Avenida Tocantins, edificações da época de sua construção segundo estilo Art Déco etc.), reforça não apenas uma ideia dominante de cidade e sobre o urbano, mas também de patrimônio, em consonância com um projeto político-econômico determinado de produção e reprodução do espaço urbano.

O estofo teórico e a grande base de dados empíricos já produzidos na linha da contribuição teórico-metodológica relacionada têm contribuído crescentemente para conferir, por um lado, visibilidade às múltiplas e até recentemente ignoradas temporalidades/experiências constitutivas do urbano na mesma. Por outro lado, têm colaborado também para a própria crítica da concepção de patrimônio sobre a qual já nos debruçamos. Tais investigações, assim, nos impõem o desafio de problematizarmos ininterruptamente a temporalidade oficialmente instituída da cidade em questão, e a urgência de estranhar o que geralmente nos é dado a ler sobre a mesma no âmbito 
Goiânia: dinâmicas do patrimônio e da memória entre a instituição...

da cidade das letras, como resultante da centralidade conferida à oralidade e à memória no processo de análise.

Essas contribuições analíticas promoveram um aceleramento da crise da referida ideia de patrimônio e do conceito de cultura implícito na mesma. Assim, fragilizando discursos daí derivados em geral -, porque incapazes de acolher a polissemia do urbano e de suas memórias e diversos sujeitos enquanto parte do compósito deste. Opostamente a isso, o modelo de patrimônio discutido e associado à imagem de Goiânia enquanto cidade-monumento seguiu agonizante até o início do último quarto do século XX. A ideia era sustentar a visão de história fundada com base num processo no qual "[...] tradições populares são subjugadas a outras tantas tradições inventadas na perspectiva de ocultar os conflitos e produzir a imagem de uma sociedade harmônica" (HOBSBAWM, 2008, p. 17).

Essas inúmeras outras memórias sobre o urbano, tradicionalmente silenciadas no âmbito de suas relações com cidade e cultura, memória e patrimônio, a partir desse momento (caracterizado por uma profunda revisão teórica e metodológica) passaram progressivamente a serem analisadas conferindo-se centralidade à categoria espaço como algo carregado de significados e de possibilidades, já que é atravessado por múltiplas temporalidades que o ressignificam constantemente (KHOURY, 1993). Assim, prática e cotidianamente, desafia-se a referida narrativa da cidade-monumento/ cidade-patrimônio.

Nesse contexto de expressiva revisão do vigente paradigma de patrimônio e ideias alimentadas pelo mesmo, certamente foram determinantes os movimentos sociais no Brasil a partir das décadas de 1970 e 1980, em torno de uma agenda multifacetada: moradia; emprego; educação; saúde; democracia; cidadania; igualdade nas relações de gênero, etc. Tais questões foram fundamentais no campo de batalhas, do qual resultou a conquista de vários direitos sociais, que foram inscritos em leis na nova Constituição Federal de 1988 (GHON, 2009a). Particularmente, houve uma profunda revisão do paradigma de patrimônio cultural. 


\section{Dinâmicas do patrimônio e da memória na atualidade: novos diálogos e desafios}

O processo de reconfiguração do campo do patrimônio cultural na atualidade tem desafiado os pesquisadores a compreenderem os usos sociais do passado, suas relações como processos de patrimonialização, tendo, em particular, a perspectiva de expansão da memória e das dinâmicas identitárias. Nessa linha, definições de bens culturais restritos a edificações típicas ou afinadas com a concepção de patrimônio enquanto cidade-monumento (RIEGL, 2006) têm sido objeto problematizado, alimentando um processo de construção de um novo horizonte de investigações da antropologia e sociologia, história e museologia, geografia e outras ciências. Desafio esse que tem sido enfrentado com grande participação de metodologias qualitativas, a partir dos anos 1970 e 1980. Tais métodos estão fundamentados, como já foi demonstrado anteriormente, numa grande massa de evidências empíricas e reflexões teóricas internacionalmente reconhecidas pela comunidade científica.

Nessa linha, Pierre Nora (1993) nos chama a atenção para o fato de que, a partir do final do século XX, constata-se mais e mais uma convergência entre história-memória e história-patrimônio. Memórias parciais reivindicam legados, além dos grandes patrimônios nacionais, processo que teve um de seus importantes marcos na Carta de 1988, no artigo 216. Nela, o patrimônio cultural figura definido como "bens de natureza material e imaterial, tomados individualmente ou em conjunto, portadores de referência à identidade, à ação, à memória dos diferentes grupos formadores da sociedade brasileira" (BRASIL, 1988). A partir de então,

[...] são passíveis de patrimonialização e salvaguarda as formas de expressão; os modos de criar; fazer e viver; as criações científicas; artísticas e tecnológicas; as obras, objetos, documentos, edificações e demais espaços destinados às manifestações artísticas e culturais; os conjuntos urbanos e sítios de valor histórico, paisagístico, artístico, arqueológico, paleontológico, ecológico e científico. Recentemente foi criado o Programa Nacional de Patrimônio Imaterial, que 
Goiânia: dinâmicas do patrimônio e da memória entre a instituição...

instituiu o Registro de Bens Culturais de Natureza Imaterial, por meio do Decreto 3.551 de 4 de agosto de 2000, enfatizando assim a necessidade de valorização de práticas culturais não visíveis até pouco tempo (ASSIS, 2016, p. 46).

Contexto histórico também marcado - em nível internacional - pelo lançamento da Recomendação de Salvaguarda das Culturas Tradicionais e Populares em 1972 e 1989, pela UNESCO, momento no qual constatamos uma forte internacionalização das políticas preservacionistas, estimulando uma dinâmica globalizada de identificação, proteção, difusão de valores e signos patrimoniais. Essa tendência de patrimonialização das diferenças constituiu um processo levado a cabo, em particular, por essa instituição e profundamente determinado pelas incertezas quanto ao futuro dos bens culturais num mundo crescentemente homogeneizado no âmbito do capitalismo globalizado e neoliberal (ABREU, 2015).

Essa dilatação do conceito de patrimônio, reforçamos, tem como pano de fundo um novo contexto sociopolítico, em particular no Brasil. Ainda, há um expressivo movimento acadêmico internacional e interdisciplinar (a partir das décadas de 1970 e 1980) de revisão de tradicionais processos de patrimonialização vinculados à produção/reprodução de uma memória em detrimento de outras. Processos que participaram determinantemente para que, superada, se tornasse "[...] a concepção puramente histórica do patrimônio cultural em favor de uma concepção abrangente de todas as expressões simbólicas da memória coletiva, constitutivas da identidade de um lugar, uma região e uma comunidade" (CAMPELLO apud SILVA, 2001, p. 101).

Esse processo de ampliação do significado de patrimônio esteve, desde sua origem, vinculado à crescente compreensão sobre a necessidade de: dissociá-lo da ideia de monumento; reconhecer o direito de visibilidade institucional relativo a outras memórias; admitir tal conceito como campo atravessado por disputas e tensões (CHAGAS; ABREU, 2003; FONSECA, 2003a). Assim influenciada, a noção tradicional de patrimônio cultural resultou ampliada, sendo que, em tal processo, "[...] novos olhares vêm sendo construídos a partir da discussão sobre o patrimônio cultural intangível ou 
patrimônio imaterial”. De outra forma, produções culturais transitórias e fugazes, saberes e performances, não materializados em produtos duráveis, em geral, são excluídos por concepções tradicionais e práticas arbitrárias de patrimônio (ASSIS, 2016).

Nesse sentido, essa nova concepção de patrimônio (imaterial) a partir de renovado conceito de cultura trabalhado por antropólogos, etnógrafos, historiadores e outros, trouxe novos elementos ao entendimento de produção cultural enquanto conjunto de relações sociais cotidianas e diversamente praticadas e (re)significadas (FONSECA, 2003a).

Para finalizar este tópico, cabe destacar que o mesmo conceito encontra-se assim definido de acordo com a UNESCO (2005): “[...] práticas, representações, expressões, conhecimentos e técnicas [...] que as comunidades, os grupos e, em alguns casos, os indivíduos reconhecem como parte integrante de seu patrimônio cultural [...]"; que são "[...] transmitidos de geração em geração [...]”; “[...] recriados pelas comunidades e grupos em função de seu ambiente, de sua interação com a natureza e de sua história [...]"; geradores de "[...] um sentimento de identidade e continuidade, contribuindo assim para promover o respeito à diversidade cultural e à criatividade humana".

Essa ampliação do conceito de patrimônio cultural enquanto construções intangíveis ou imateriais tornou-o mais plural e adequado com o seu caráter processual e fluido, proveniente das construções humanas. De outro modo, o patrimônio cultural está presente não apenas nos bens culturais materiais (ARANTES, 1981). As novas fronteiras do mesmo permitiram a este acolher em seus novos limites a ideia segundo a qual os sujeitos - de forma contextualizada - estão em constante processo de recriação de seus modos de vida, pensar e fazer. Sendo assim, uma das principais consequências de tal transformação foi "[...] o início do processo de desconstrução de algumas dicotomias paradigmáticas, como a de material $\mathrm{x}$ imaterial, cultura erudita x cultura popular, presente $\mathrm{x}$ passado e processo $\mathrm{x}$ produto, as quais passaram a ser questionadas e discutidas [...]" e uma efervescente e produtiva discussão sobre a "[...] imaterialidade do patrimônio cultural, suas particularidades e conteúdo (FONSECA, 2003b). 
Goiânia: dinâmicas do patrimônio e da memória entre a instituição...

\section{Considerações finais}

Nas últimas décadas, tal debate reforçou também um processo interdisciplinar de problematização das relações entre história e memória; memória e patrimônio; cultura e cidade; cultura $\infty$ e poder. Ademais, contribuiu para abrir espaço para o crescente reconhecimento da cidade e do urbano como produção subjetiva, multifacetada e conflituosa, formas de vida, saberes e modos de fazer no âmbito do patrimônio material e imaterial. Contribuiu também para consolidar um novo contexto, no qual metodologias qualitativas, alternativas aos tradicionais métodos de investigação, têm ajudado a viabilizar e dar visibilidade a outras memórias silenciadas ou apagadas pelos limites conceituais, estes vinculados aos predicados do que até meados dos anos 1970 foi concebido como patrimônio, em particular no que concerne ao processo de construção/urbanização de Goiânia.

Assim, é indispensável que procuremos olhar para a cidade de Goiânia não considerando a mesma abstratamente ou através dos atributos sustentados sobre ela pelas tradicionais narrativas locais. É necessário ir além do tradicional processo de patrimonialização, problematizando a convencional dicotomia cidade-monumento $\mathrm{x}$ cidades vivenciadas (silenciadas/apagadas). Trata-se do desafio de promovermos uma revisão crítica das convencionais relações entre memória e patrimônio (ABREU, 2008), constituintes, indubitavelmente, da maior parte daquilo que se encontra reconhecido como patrimônio cultural ao longo da história de Goiânia.

Finalizando, não é demais salientar, embora não seja nosso objeto neste artigo, que, atualmente, o debate em questão tornou-se certamente um dos elementos promotores de uma histeria patrimonial, representada pelo "[...] extenso uso do conceito de patrimônio nos mais diversos discursos, bem como por uma busca desenfreada por alguma forma de patrimônio nas comunidades", fato esse "[...] associado aos fenômenos de fragmentação e mercantilização da cultura [...]”. Em grande medida, devido à própria dinâmica que vincula mais e mais o patrimônio material e imaterial à esfera da circulação global de valores, signos e mercadorias (PEIXOTO, 2010 apud ALMEIDA, 2017, p. 93-94). 
Essa se configura como uma tendência contemporânea que, não raramente, é acompanhada de estratégias de revalorização do território enquanto mercadoria vendável, parcial ou totalmente, no mercado global ${ }^{8}$. De outra forma, e na mesma linha, processos que tendem a segregar e refuncionalizar espaços e, muito comumente, resultando em sistemática destituição de antigas populações que viviam em áreas que se tornam reconhecidas como patrimônio cultural. Além disso, tendem a ficar privados da vida e do acesso às mesmas, dado que, nesse processo, as práticas sociais de consumo cultural passam a ser orientadas pela lógica excludente da mercadoria (PAES-LUCHIARI, 2005).

\section{GOIÂNIA: DYNAMICS OF EQUITY AND MEMORY BETWEEN THE INSTITUTION OF CITY-MONUMENT AND THE CITY-PRACTICED: DIALOGUES AND CHALLENGES}

Abstract: The process of reconfiguration of the field of cultural heritage today has challenged researchers to understand the social uses of the past and their relationships with the dynamics of patrimonialization, understood as a process in a context marked by the expansion of memory and identity dynamics. The construction of this new deeply interdisciplinary horizon is evident, with a great recurrence of qualitative methodologies from the 1970s and 1980s. This process is also characterized by the deconstruction of paradigmatic dichotomies: material $\mathrm{x}$ immaterial; erudite culture vs. popular culture; present $\mathrm{x}$ past; memory $\mathrm{x}$ history, etc. This article develops such a discussion from the analysis of dominant narratives about the urban and the city of Goiânia-GO and its relations with two different conceptions of cultural heritage, from its foundation in 1937 until the end of the twentieth century.

Keywords: Cultural heritage. Patrimonialization. History. Memory. City.

\section{Notas}

${ }^{1}$ Segundo Almeida e Araújo (2007, p. 3-4), "[...] Goiânia se insere no contexto do Patrimônio Cultural através de seu Centro Histórico no qual, através da Portaria 507, de 18 de novembro de 2003, publicada no Diário Oficial da União, em 24 de novembro do mesmo ano, foram tombados pelo IPHAN (Instituto do Patrimônio Histórico e Artístico Nacional). [...] O tombamento é um instrumento jurídico que coloca sob proteção do Estado os bens de 
Goiânia: dinâmicas do patrimônio e da memória entre a instituição...

natureza material cuja preservação seja de interesse público". Sendo que, em Goiânia, dentre os bens tombados, destacam-se: "[...] os componentes do núcleo urbanístico inicial: vias; organização de quadras; edifícios e o núcleo urbano histórico de Campinas. No núcleo pioneiro, destaca-se a Praça Cívica, que faz parte do desenho urbano do plano original de Goiânia e possui edifícios que fizeram parte dessa região germinal da cidade, incluindo-se entre os bens do conjunto urbanístico e arquitetônico Art Déco. Todavia, antes disso, esse conjunto arquitetônico e urbano já se encontrava protegido por leis estaduais e municipais, além de estar diretamente ligado ao desenvolvimento das atividades públicas destas instâncias."

${ }^{2}$ Em 1932, decreto estadual no 1816 , de 23-03-1937 transfere a capital do estado do município de Goiás para Goiânia. "[...] a materialização da construção de Goiânia iria de encontro com o ideário de modernidade que a Marcha para o Oeste pulverizava e atenderia também os interesses de grupos vinculados às regiões mais ricas do Estado, sul, sudeste e sudoeste. Sendo Pedro Ludovico representante destas, defendia deslocar o poder político para próximo das regiões economicamente mais prósperas do estado e onde estava sua base política. Consequentemente enfraqueceria os grupos opositores, que cada vez mais eram associados à imagem de atraso que se construiu em Goiás na Primeira República. Visando atender os objetivos traçados, em nome de uma nova Capital para o Estado, se dinamizava uma Capital para o Sul e Sudoeste, ou seja, para o centro econômico do Estado" (CHAUL, 1988, p. 78).

${ }^{3}$ Nesse sentido, Oliveira (2018, p. 190) escreve: “O Álbum de Fotografias sobre o Planejamento e Construção da Cidade de Goiânia, de 1935, oferecido pelo então governador goiano Pedro Ludovico Teixeira ao presidente da República, Getúlio Vargas, demonstrava, com propriedade, os discursos vinculados à mudança da capital do Estado. As fotos encardidas da cidade de Goiás escondiam-se atrás da pujança das obras da moderna Goiânia. A outrora Vila Boa era apresentada como se estivesse congelada no tempo e ressaltando aspectos pacatos e rurais ruas sem calçamento, cavalos e carroças perambulando pelos espaços públicos -, em uma demonstração de vínculos indissolúveis com os séculos anteriores. Goiânia, ao contrário, era mostrada como ícone da modernidade, por meio da sua arquitetura sem adereços historicistas, do campo de pouso com o avião da Vasp, das ruas pavimentadas, das alamedas retilíneas arborizadas, entre outros. [...] A imagem perpetuada do sertão - identificado com o atraso e preso ao meio rural - colava-se à Cidade de Goiás, ao contrário de Goiânia, que era a porta para o mundo moderno e urbano".

${ }^{4}$ Ver: Fonseca (2009); Calebre (2009); Gonçalves (2002); Pereira (2012); Sant'Anna (2014).

Anos 90, Porto Alegre, v. 25, n. 48, p. 275-296, dez. 2018 
${ }^{5}$ Sobre o que aqui definimos como cidade-postal, são muito esclarecedoras as palavras de Pesavento (2007, p. 5) ao apresentar tal fenômeno como "[...] desdobramento das abordagens que se fazem sobre o fenômeno urbano no final do século XX e no início do novo século, não se estudam apenas processos econômicos e sociais que ocorrem na cidade, mas as representações que se constroem na e sobre a cidade, ou seja, com o imaginário criado sobre ela. Em outras palavras, os estudos de uma história cultural urbana se aplicam no resgate dos discursos, imagens e práticas sociais de representação da cidade. E o imaginário urbano, como todo o imaginário, diz respeito a formas de percepção, identificação e atribuição de significados ao mundo, o que implica dizer que trata das representações construídas sobre a realidade no caso, a cidade”.

${ }^{6}$ A transferência definitiva da capital do Estado de Goiás (da cidade de Goiás para Goiânia) implicou também na continuidade de um processo anterior que apresentava esta como símbolo da modernidade ou progresso. "[...] A partir daí, Goiânia assume os holofotes e a Cidade de Goiás cai no ostracismo esperado. Afinal, a modernidade [grifo do autor] almejada vinha pelos trilhos do trem, mas materializava-se na cidade de ruas largas e arborizadas, por meio de suas construções Art Déco. O asfalto substituía a pedra, assim como o tijolo ocupava o lugar do adobe e o carro atropelava o cavalo.” (OLIVEIRA, 2018, p. 192).

${ }^{7}$ Hobsbawn (1972); Le Goff (1977; 1979; 1988); Williams (1979; 1990); Thompson (1981; 1987; 1988; 1991); Fernández Delgado (1982); Schwartz (1982); Bodnar (1989); Bourguet, Valensi e Wachtel (1990); Jedlowski e Rampazzi (1991); Kammen (1991); Nora (1992); Peyras (1993); Dahian-Smith e Hamilton (1994); Cuesta (1995); Madalena (1996); Choay (2010; 2011); Jeudy (2005); Hartog, (2018); Revel (2010); Almeida e Rovai (2011); Abreu e Chagas (2012); Gonçalves (2002); Hobsbwam e Ranger (2012); Velho (2006) etc.

${ }^{8}$ Ver: Harvey (1996); Warner (2000); Borja e Castells (1997), Choay (2010).

\section{Referências}

ABREU, Regina. Patrimônios Etnográficos e museus: uma visão antropológica. In: ___ E o patrimônio? Rio de Janeiro: Contra-Capa, 2008.

ABREU, Regina; CHAGAS, Mario. Memória e Patrimônio: ensaios contemporâneos. Rio de Janeiro: Lamparina, 2009. In: PAULA, Zuleide Casagrande de (Org.). Polifonia do patrimônio. Londrina: EDUEL, 2012. 
Goiânia: dinâmicas do patrimônio e da memória entre a instituição...

ALMEIDA, Maria Geralda de; ARAÚJO, Márcia de. Núcleo pioneiro de Goiânia: um patrimônio inteligível? In: EREGEO SIMPÓSIO REGIONAL DE GEOGRAFIA. ABORDAGENS GEOGRÁFICAS DO CERRADO, 10., 2007, Catalão. Anais... Catalão, GO: UFG; Campus Catalão, 2007.

ALMEIDA, Maisa. Processos urbanos e patrimonialização mundial: espaços de contradição e ressignificação dos tecidos urbanos patrimoniais. 2017. Tese (Doutorado em Arquitetura e Urbanismo, Teoria e História da Arquitetura e do Urbanismo)-Instituto de Arquitetura e Urbanismo, Universidade de São Paulo, São Paulo, 2017.

ALMEIDA, Juniele Rabelô de; ROVAI, Marta de Oliveira (Org.). Introdução à história pública. São Paulo: Letra e Voz, 2011.

ARANTES, Antônio Augusto. O que é cultura popular. São Paulo: Brasiliense, 1981.

ASSIS, Neiva de. Cidade Polifônica: indícios de memórias outras na paisagem. 2016. Tese (Doutorado em Psicologia)-Programa de Pós-Graduação em Psicologia, Centro de Filosofia e Ciências Humanas da Universidade Federal de Santa Catarina, Florianopólis, 2016.

BENJAMIN, W. Teses sobre o conceito da história. In: LÖWY, M. Alarme de incêndio: uma leitura das teses sobre o conceito de história. São Paulo: Boitempo Editorial, 2005.

BODNAR, E. Power and Memory in Oral-History. Workers and Managers at Studebaker. Joumal of American History, v. 75, n. 4, p. 1201-1221, 1989.

BORGES, Barsanulfo Gomides. O despertar dos dormentes. Goiânia: Universidade Federal de Goiás, 1982.

BORJA, Jordi; CASTELLS, Manuel. Local y global. La gestión de las ciudades en la era de la información. Madrid: United Nationsfor Human Sttlements/ Taurus/Pensamiento, 1997.

BOURGUET, Marie-Noelle; VALENSI, Lucetti; WACHTEL, Nathan (Ed.). Between memory and history. Chur: Harwood Academic Publishers, 1990.

CALABRE, Lia. Políticas culturais no Brasil: dos anos 1930 ao século XXI. Rio de Janeiro: Editora FGV, 2009.

CALVINO, Ítalo. A palavra escrita e a não-escrita. In: FERREIRA, Marieta de Moraes; AMADO, Janaína (Org.). Usos e abusos da história oral. Rio de Janeiro: Fundação Getúlio Vargas, 1996.

CAMPELLO, G. Ações pelo patrimônio. Disponível em: <http://minc.gov.br/ textos/olhar/acoespatrimonio.htm>. Acesso em: 25 fev. 2018.

Anos 90, Porto Alegre, v. 25, n. 48, p. 275-296, dez. 2018 
CERTEAU, Michel. A invenção do cotidiano: 1. Artes de Fazer. Rio de Janeiro: Vozes, 1994.

CERTEAU, Michel; GIARD, Luce; MAYOL, Pierre. A invenção do cotidiano: 2. Morar e Cozinhar. Rio de Janeiro: Vozes, 1997.

CHAGAS, Francisco das. Dos lugares de memória ao patrimônio: emergência e transformação da 'problemática dos lugares'. Projeto História, São Paulo, n. 52, p. 245-279, jan./abr. 2015. Disponível em: <https://revistas.pucsp.br/index. php/revph/article/viewFile/21370/18609>. Acesso em: 12 fev. 2018.

CHAGAS, Mário; ABREU, Regina (Org.). Introdução. In: Memória e patrimônio: ensaios contemporâneos. Rio de Janeiro: DP\&A, 2003.

CHAUL, N. F. A construção de Goiânia e a transferência da capital. Goiânia: Cegraf UFG, 1988.

. Caminhos de Goiás: da construção da decadência aos limites da modernidade. Goiânia: Editora UFG, 1997.

CHAVES, Elza Guedes. De invasor a posseiro: estado-igreja e a luta pela terra urbana. 1985. Dissertação (Mestrado em Antropologia)-Universidade Federal da Paraíba, João Pessoa, 1985.

CHOAY, Françoise. Alegoria do patrimônio. Coimbra: Edições 70, 2010.

CHOAY, Françoise (Org.). O Patrimônio em questão: antologia para um combate. Belo Horizonte: Editora Fino Traço, 2011.

CUESTA, I. De la memoria a la historia. In: ALTED VICIL, A. Entre el pasado y el presente. Historia y memoria. Madrid: UNED, 1995.

DAHIAN-SMITH, K.; HAMILTON, P. (Ed.): Memory and history in twentiethcentury. Australia, Melbourne: Oxford University Press, 1994.

FERNÁNDEZ DELGADO, J. et al. La memoria impuesta. Estudio y Catálogo de los Monumentos Conmemorativos de Madrid (1939-1980). Madrid: Ayuntamiento, 1982.

FONSECA, Maria Cecília Londres. Para além da pedra e cal: por uma concepção ampla de patrimônio cultural. In: ABREU, Regina; CHAGAS, Mário (Org.). Memória e patrimônio: ensaios contemporâneos. Rio de Janeiro: DP\&A, 2003a.

. Patrimônio e Performance: uma relação interessante. In: TEIXEIRA, João Gabriel Lima Cruz; GARCIA, Marcos Carvalho; GUSMÃO, Rita. Patrimônio imaterial, performance, cultura e retradicionalização. Brasília, DF: TRANSE/ CEAM; Universidade de Brasília, 2003b. 
Goiânia: dinâmicas do patrimônio e da memória entre a instituição...

. O patrimônio em processo: trajetória da política federal de preservação no Brasil. Rio de Janeiro: UFRJ/IPHAN, 2009.

GONÇALVES, José Reginaldo Santos. A retórica da perda: os discursos do patrimônio cultural no Brasil. Rio de Janeiro: Editora UFRJ; Ministério da Cultura; IPHAN, 2002.

HARTOG, François. Tempo e patrimônio. Varia História, Belo Horizonte, v. 22, n. 36, p. 261-273, 2006. Disponível em: <http://scielo.br/pdf/vh/v22n36/ v22n36a02.pdf >. Acesso em: 7 mar. 2018.

. Regimes de Historicidade: presentismo e experiência do tempo. Belo Horizonte: Editora Autêntica, 2013.

HARVEY, David. Do gerenciamento ao empresariamento: a transformação da administração urbana no capitalismo tardio. Espaço e Debates, São Paulo, n. 39, p. 48-64, 1996.

HOBSBAWM, Eric. The social function of the past: some questions. Past \& Present, Londres, v. 55, n. 1, p. 3-17, 1972.

HOBSBAWM, Eric; RANGER, Terence (Org.). A invenção das tradições. São Paulo: Paz e Terra, 2012.

JEDLOWSKI, Paolo; RAMPAZZI, Marita (Org.). Il senso del passato: per una sociologia della memoria. Milão: Angeli, 1991.

JEUDY, Henri-Pierre. O espelho das cidades. Rio de Janeiro: Casa da Palavra, 2005.

KAMMEN, M. Mystic chords of memory. The Transformation of Tradition in American Culture. Nueva York: Alfred Knopf Ed., 1991.

LE GOFF, J. El orden de la memoria. El tiempo como imaginario. Barcelona: Paidós, 1991 [1977].

. Documento/Monumento. Enciclopedia Einaudi, Turín, Einaudi, v. 5, p. 38-48, 1979.

. Historie et mémoire. Paris: Gallimard, 1988.

MADALENA, José Ignacio; GRUPO SALAMANCA. La memoria y el poder: los cambios en la denominación de las calles de Valladolid, Salamanca y León. In: VIGIL, Alicia (Coord.). Entre el pasado y el presente: historia y memoria. Madrid: UNED, 1996.

MENESES, Ulpiano Toledo Bezerra de. O campo do Patrimônio Cultural: uma revisão de premissas. FÓRUM NACIONAL DO PATRIMÔNIO CULTURAL, 1., 2009, Ouro Preto. Anais... Ouro Preto, MG, 2009. Disponível em: <http:// iphan.gov.br/baixaFcdAnexo.do?id=3306>. Acesso em: 3 out. 2017.

Anos 90, Porto Alegre, v. 25, n. 48, p. 275-296, dez. 2018 
. Cultura e cidades. Revista Brasileira de História, São Paulo, ANPUH, n. 8/9, 1985.

MONTEIRO, Ofélia do Nascimento. Como nasceu Goiânia. São Paulo: Empresa Gráfica, Revista dos Tribunais, 1938.

NORA, Pierre. Comment écrire l'historie de France? In: NORA, Pierre (Org.). Les lieux de mémoire III: Les France 1 conflits et partages. Paris: Gallimard, 1992. OLIVEIRA, Adriana Mara Vaz de. A percepção da mudança: os registros na cidade de Goiás. História, São Paulo, v. 30, n. 1, p. 189-208, jan/jun, 2011. Disponível em: 〈http://scielo.br/pdf/his/v30n1/v30n1a09.pdf>. Acesso em: 12 set. 2018.

PAES-LUCHIARI, Maria Tereza. Centros históricos: mercantilização e territorialidades do patrimônio cultural urbano. Revista do Programa de Pós-Graduação em Geografia da Universidade Federal de Niterói, Niterói, v. 7, n. 14, 2005. Disponível em: <http://geographia.uff.br/index.php/geographia/article/ view/165>. Acesso em: 23 fev. 2018.

PALACÍN, Luis; MORAES, Maria Augusta de Sant'Anna Moraes. História de Goiás: 1722-1972. Goiânia: Imprensa da UFG, 1975.

PEIXOTO, Paulo. Patrimônios mundiais: Fragmentação e Mercantilização da Cultura. São Paulo: Instituto Camões; CES Patrimônios de Influência Portuguesa, 2010.

PEREIRA, Julia Wagner. O tombamento: de instrumento a processo na construção de uma ideia de nação. In: CHUVA, Márcia; NOGUEIRA, Antônio Gilberto (Org.). Patrimônio Cultural: políticas e perspectivas de preservação no Brasil. Rio de Janeiro: Mauad X; FAPERJ, 2012.

PESAVENTO, Sandra Jatahy. Cidades visíveis, cidades sensíveis, cidades imaginárias. Revista Brasileira de História, São Paulo, v. 27, n. 53, jan./jun. 2007. Disponível em: $\langle$ http://scielo.br/scielo.php?script=sci_arttext\&pi$\mathrm{d}=$ S0102-01882007000100002>. Acesso em: 11 set. 2018.

PEYRAS, I. Les Monuments et la mémoire. Textes [St-Denis]. Saint Denis: Centre de recherches litteraires et historiques de l'Universite de La Reunion, 1993.

RAMA, Angel. A cidade das letras. São Paulo: Brasiliense, 1989.

REVEL, J. O fardo da memória. In: . História e Historiografia: exercícios críticos. Curitiba: EDUFPR, 2010.

RIEGL, Alois. O culto moderno dos monumentos: sua essência e sua origem. São Paulo: Editora Perspectiva, 2014. 
Goiânia: dinâmicas do patrimônio e da memória entre a instituição...

SCHWARTZ, B. The social context of commemoration: a study in collective memory. Social Forces, v. 6, n. 1, p. 374-402, 1982.

SCIFONI, S. A construção do patrimônio natural. Tese (Doutorado em Geografia Humana)-Faculdade de Filosofia, Letras e Ciências Humanas, Universidade de São Paulo, São Paulo, 2006. 293 f.

SILVA, J. A. da. Ordenação constitucional da cultura. São Paulo: Malheiros, 2001. THOMPSON, E. P. A miséria da teoria: ou um planetário dos erros. Rio de Janeiro: Zahar, 1981.

Zahar, 1987.

- A formação da classe operária: a árvore da liberdade. Rio de Janeiro: . La voz del pasado. História oral. Valencia: Alfonso el Magnanim, 1988.

. O Tempo, a disciplina do trabalho e o capitalismo industrial. In: SILVA, Tomaz Tadeu (Org.). Trabalho, educação e prática social: por uma teoria da formação humana. Porto Alegre: Artes Médicas, 1991.

UNESCO. Declaração Universal sobre a Diversidade Cultural. Disponível em: <www.unesco.org.br>. Acesso em: 23 mar. 2018.

WILLIAMS, Raymond. Marxismo e literatura. Rio de Janeiro: Zahar Editores, 1979.

. O campo e a cidade: na história e na literatura. São Paulo: Companhia das Letras, 1990.

WARNIER, Jean-Pierre. A mundialização da cultura. Bauru: EDUSC, 2000.

VELHO, G. Patrimônio, negociação e conflito. Mana, v. 12, n. 1, 2006. Disponível em: <http://scielo.br/scielo.php?script=sci_arttext\&pid=S0104-93132006000100009>. Acesso em: 19 fev. 2018.

Recebido em: 29/04/2018

Aprovado em: 10/08/2018

Anos 90, Porto Alegre, v. 25, n. 48, p. 275-296, dez. 2018 